\title{
Metabolic Syndrome in Hypertensive Nigerians: Risk Factor Analysis
}

\author{
Innocent S. I. Ogbu ${ }^{1,}$ Emmanuel Ike Ugwuja ${ }^{2}$ \\ ${ }^{I}$ Department of Medical Laboratory Sciences, Faculty of Health Sciences and Technology, College of Medicine, \\ University of Nigeria, Enugu Campus, Nigeria \\ ${ }^{2}$ Department of Chemical Pathology, faculty of Clinical Medicine, Ebonyi State University, P.M.B. 053, \\ Abakaliki, Nigeria.
}

\begin{abstract}
Objectives: To determine the prevalence of metabolic syndrome (MS) and adequacy of the National Cholesterol Education Programme/ Adult Treatment Panel III (ATP III) criteria for the diagnosis of the MS in hypertensive Nigerians. Materials and Methods: Four hundred and thirty six hypertensive patients, (men 49 $\%)$, aged $\geq 35$ years who were randomly recruited from Medical Outpatient clinics of the University of Nigeria Teaching Hospital, Enugu, Nigeria were studied. Waist circumference (WC) and blood pressure (BP) were measured in addition to fasting plasma glucose (FPG), Triglyceride (TG) and high density lipoproteincholesterol (HDL-C) using standard laboratory techniques. Results: MS prevalence of $45.6 \%$ was recorded with more women (54\%) than men (36.4\%) having the syndrome. Sex-specific and significant differences were recorded only in waist circumference $(W C)(<0.05)$ of the subjects with the female subjects recording higher mean value $(98.9 \pm 13.3 \mathrm{~cm})$ than the male patients $(93.2 \pm 12.9 \mathrm{~cm})$. The ATP III criterion for WC $(>102 \mathrm{~cm})$ gave sensitivity of $69.4 \%$, specificity $(71.6 \%)$, positive predictive value (PPV) of $67.2 \%$ and odd ratio $(O R)$ of 5.7 among the males-plus-females patients. There were improvement in these indices when a WC $\geq 93 \mathrm{~cm}$ was used with values of $79.9 \%, 62.9 \%, 72 \%$ and 6.7 for sensitivity, specificity, PPV and OR respectively and MS prevalence of $54.4 \%$ with improvement most significant among the male subjects. The ATP III criterion for female $W C$ (>88cm) gave a low specificity (41.7\%), which improved (46.1\%) when WC $\geq 93 \mathrm{~cm}$ was used. While the ATP III criterion for HDL-C gave low predictive indices for male, but improved when 1.3mmol/l was used, it was adequate for the female subjects. However, while the ATP III criterion for TG was adequate in all the groups, it gave low predictive values for FPG, with better results among the males than in the females

Conclusions: The ATP III criteria were not wholly suitable for the diagnosis of the MS in the hypertensive Nigerians. The criteria exhibited sex-specific variations in their predictive potentials. WC $(\geq 93 \mathrm{~cm})$ for men and women, raised fasting $T G(\geq 1.70 \mathrm{mmol} / 10$, raised $B P(\geq 130 / 85 \mathrm{mmHg})$, low $H D L-C(\leq 1.3 \mathrm{mmol} / \mathrm{l})$ for men and women, $F P G(>5.6 \mathrm{mmol} / \mathrm{l})$ were suggested as more appropriate for the diagnosis of $M S$ in the study population. Key words: Metabolic syndrome, ATP III criteria, dyslipidaemia, hyperglycaemia, hypertensive Nigerians.
\end{abstract}

\section{Introduction}

Metabolic syndrome (MS), an increasing public health problem is characterized by truncal obesity, elevated blood pressure (BP), dyslipidaemia, hyperglycaemia and insulin resistance (IR) [1-4]. Several criteria have been put forward for the diagnosis of MS [2, 3-5]. They differ both in the number, variety and cut-off points of the risk factors. Hyperglycaemia, hypertriglyceridaemia, low high density lipoprotein cholesterol (HDL-C), elevated BP and a measure of obesity or overweight are constant factors. The National Cholesterol Education/Adult Treatment Panel III (ATP III) [3] recommendations is the most popular but it was meant for the US population [5]. There have been modifications and clarifications of the criteria to allow for individual and ethnic variations in the risk factors [5]. The International Diabetes Federation (IDF) [4] criteria placed emphasis on waist circumference (WC) as a requirement for the diagnosis of MS while the ATP III criteria did not deem it necessary if 3 other risk factors were present. The World Health Organization (WHO) [2] and American Association of Clinical Endocrinologists (AACE) [5] criteria included body mass index (BMI), but with different cut-off points. The former recommended a BMI $>30 \mathrm{~kg} / \mathrm{m}^{2}$ while the later has BMI $>25 \mathrm{~kg} / \mathrm{m}^{2}$. The WHO criteria also incorporated waist-hip ratio (WHR) as a factor and has a higher cut-off point for BP $(140 / 90 \mathrm{mmHg})$ than others $(130 / 85 \mathrm{mmHg})$. There is no agreement on the cut-off point for high density lipoprotein-cholesterol (HDL-C) either for men or women. While WHO recommended $<0.88$ and < $0.98 \mathrm{mmol} / 1$, AACE has $<1.0$ and $<1.3 \mathrm{mmol} / 1$ and ATP III and IDF have $\leq 1.0$ and $\leq 1.3 \mathrm{mmol} / 1$ for men and women respectively. For hyperglycaemia, ATP III and IDF have $\geq 5.6 \mathrm{mmol} / 1$, WHO $(5.6-6.9 \mathrm{mmol} / \mathrm{l})$ and AACE $(6.1-7.0 \mathrm{mmol} / \mathrm{l})$. Recently a new joint statement was issued by a number of professional organizations which include the IDF, National Heart, Lung, and Blood Institute (NHLBI), World Heart Federation (WHF), International Atherosclerosis Society (IAS), and American Heart Association (AHA) that claimed elimination of some of the confusion regarding how to identify patients with MS [6]. This statement allotted no figures to WC 
stating that it is "population and country specific". It also stressed that drug treatment for a condition is evidence of the presence of the condition [6]. Besides these, the new criteria did not differ from the ATP III criteria. These figures differ considerably and introduce elements of confusion in the diagnosis of MS. Several studies of different ethnic groups suggest different patterns of clustering of risk factors as well as prevalence among men and women [7-9] suggesting variations in the significance of the factors as features of the syndrome in different ethnic groups as a result of variations in body proportions among persons. Ethnic-specific values have been advocated and defined for Chinese, Japanese and South Asians based on this fact [9-12].

There is therefore the need to analyze these factors in order to determine their suitability or otherwise for use in populations they were not originally designed for. This is what this study aims to achieve for hypertensive Nigerians. The study also aims to recommend a set of criteria for the diagnosis of the MS in the study population if the existing ones were found not suitable.

\section{Materials and Methods}

Four hundred and thirty-six, (436), hypertensive outpatients, (men 214; women 222), aged $\geq 35$ years attending the Medical Outpatient clinics of the University of Nigeria Teaching Hospital, Enugu southeastern Nigeria, participated in the study. The Ethics Committee of the Hospital approved the study protocol and informed consent was obtained from all the subjects before data and sample collections. The subjects were on combined anti-hypertensive therapy with Aspirin, Nifidipine, Frusemide and Felodipine as the mainline drugs. Exclusion criteria consisted of secondary hypertension, clinical or laboratory evidence of congestive heart failure, coronary artery disease, history of cerebro-vascular accident, valvular heart disease or diabetes mellitus.

Waist circumference was measured to the nearest $0.5 \mathrm{~cm}$ at a level midway between the lowest rib and the iliac crest using measuring tape. Fasting blood samples $(5 \mathrm{ml})$ were collected from patients between 8 am and $11 \mathrm{am}$ each day using standard methods. Two millilitre of blood sample was dispensed into fluoride oxalate tube and spun at 3000g for 5 minutes and the plasma was used for glucose estimation. The rest of the sample was put into a plain tube and allowed to clot and retract at room temperature. They were similarly spun and the serum harvested and used for the determination of triglyceride (TG) and high density lipoprotein-cholesterol (HDL-C). Plasma glucose was determined by the method of Trinder [13] while serum TG by the method of Buccolo and David [14]. HDL-C was estimated in the serum supernatant after precipitating $\beta$-apoprotein containing lipoproteins using the method of Allain et al.[15]. Cromatest ${ }^{(R)}$ mono-reagent test kits were used for biochemical determinations.

Analyses of data were done with GraphPad Prism version 2 statistical programme. MS was diagnosed in the presence of any three of the following factors: excess WC, men $>102 \mathrm{~cm}$, women $>88 \mathrm{~cm}$; raised fasting $\mathrm{TG}, \geq 1.70 \mathrm{mmol} / \mathrm{l}$; raised $\mathrm{BP}>130 / 85 \mathrm{mmHg}$ or antihypertensive therapy, low HDL-C, men $\leq 1.0 \mathrm{mmol} / 1$, women $\leq 1.3 \mathrm{mmol} / 1$ and raised $\mathrm{FPG} \geq 5.6 \mathrm{mmol} / 1[3]$.

Odd ratio $(\mathrm{OR})$, sensitivity, specificity, positive predictive value (PPV) and prevalence were calculated using standard formulae [16]. In cases where these indices were found to be too low, alternative cut-off points were suggested and compared with the ATP III figures.

\section{Results and Discussion}

A total of 198 hypertensive patients had MS giving a prevalence of $45.4 \%$. This was made up of 78 men and 120 women giving prevalence of $36.4 \%$ and 54\% among the male and female subjects respectively (data not shown). MS prevalence of $45.4 \%$ recorded in the present study is lower than $71.6 \%$ reported by Kelminda and Leila in Brazil [17] but higher than $34 \%$ by Sorkhou et al in Kuwait [18], using the same criteria. Record of MS prevalence among male and female patients separately was not encountered at the time of this report. Only WC showed significant male-female difference $(\mathrm{p}<0.05)$. Female subjects had higher mean WC $(98.9 \mathrm{~cm})$ than their male counterparts $(93.9 \mathrm{~cm})($ Table 1$)$.

Table 1: Clinical characteristics of the hypertensive patients

\begin{tabular}{lllll}
\hline Parameter & $\begin{array}{l}\text { All Patients } \\
(\mathrm{N}=436)\end{array}$ & $\begin{array}{l}\text { Male } \\
(\mathrm{n}=214)\end{array}$ & $\begin{array}{l}\text { Female } \\
(\mathrm{n}=222)\end{array}$ & p-values \\
\hline FPG $(\mathrm{mmol} / \mathrm{l})$ & $6.0 \pm 3.3$ & $6.4 \pm 3.5$ & $5.5 \pm 3.0$ & $\mathrm{NS}$ \\
FTG $(\mathrm{mmol} / \mathrm{l})$ & $1.7 \pm 0.6$ & $1.7 \pm 0.6$ & $1.7 \pm 0.6$ & $\mathrm{NS}$ \\
HDL-C $(\mathrm{mmol} / \mathrm{l})$ & $1.4 \pm 0.4$ & $1.4 \pm 0.4$ & $1.4 \pm 0.4$ & $\mathrm{NS}$ \\
& & & & \\
DBP $(\mathrm{mm} / \mathrm{Hg})$ & $92 \pm 15$ & $90 \pm 16$ & $93 \pm 15$ & $\mathrm{NS}$ \\
SBP $(\mathrm{mm} / \mathrm{Hg})$ & $156 \pm 27$ & $162 \pm 24$ & $149 \pm 28$ & $\mathrm{~S}$ \\
& & & & $\mathrm{~S}$ \\
WC $(\mathrm{cm})$ & $95.7 \pm 13.9$ & $93.2 \pm 12.9$ & $98.9 \pm 13.3$ & \\
\hline
\end{tabular}


Values are mean \pm Standard deviation.

FPG: Fasting plasma glucose; FTG: Fasting triglyceride; HDL-C: High density lipoprotein-cholesterol; DBP: Diastolic blood pressure; SBP: Systolic blood pressure; WC: Waist circumference

This seems not to justify the assignment of higher cut-off point of WC to the male than to the female subjects by the ATP III and IDF criteria [3, 4].

The ATP III cut-off point for WC of men (>102cm) gave low sensitivity (38.5\%), low OR (3.8) and moderate PPV (58.8\%), but had a high specificity (86\%). This indicates that the cut-off point was too high for the study population. However, substituting $\geq 90 \mathrm{~cm}$ in place of $>102 \mathrm{~cm}$ only improved the sensitivity and PPV ( $90 \%$ each), but worsened the specificity and OR while giving the same prevalence (34.2\%). Further substitution with $\geq 93 \mathrm{~cm}$ improved all aspects of the predictive potential of WC. Among the female subjects however, WC cut-off point of $>88 \mathrm{~cm}$ seemed adequate for the diagnosis of the MS but for its low specificity (41.7\%). Substituting $\geq 93 \mathrm{~cm}$ produced marginal improvement only in the specificity (46.1\%) while substituting $\geq 90 \mathrm{~cm}$ had no advantage over $>88 \mathrm{~cm}$ (Table 3 ). In the general patients population WC of $\geq 93 \mathrm{~cm}$ has better predictive potential than $\geq 90 \mathrm{~cm}$ or $>102$ and $>88 \mathrm{~cm}$ (Table 2 ).

Table 2: Calculated predictive indices using the ATP III and suggested cut-off points for male, female and general hypertensive subjects.

\begin{tabular}{llllll}
\hline & WC $(\mathrm{cm})$ & FPG $(5.6$ & TG $>1.7$ & HDL $<$ & HDL $<1.3$ \\
$(\mathrm{mmol} / \mathrm{l})$ & 1.0 & $1 \mathrm{mmol} / \mathrm{l})$ \\
& & & $\mathrm{mmol} / \mathrm{l})$ & $(\mathrm{mmo} / \mathrm{l})$ &
\end{tabular}

\begin{tabular}{llllllll}
\hline Male & & & & & & \\
Sensitivity (\%) & 38.5 & 69. & 70 & 53.8 & 6.2 & 30.8 & 65 \\
& & 2 & & & & & \\
Specificity (\%) & 86 & 60 & 75 & 78 & 68 & 88 & 83 \\
PPV (\%) & 58.8 & 90 & 90 & 56 & 61 & 57 & 81.3 \\
OR (n) & 3.8 & 3.4 & 3.4 & 4.1 & 53 & 3.3 & 9.2 \\
Prevalence (\%) & 34.2 & 34. & 52.6 & 34.2 & 34.2 & 34.2 & 52.6 \\
& & 2 & & & & & \\
Female & & & & & & & \\
Sensitivity (\%) & 91.7 & 86. & 91.2 & 25 & 63.9 & 66.7 & - \\
Specificity (\%) & 41.7 & 41. & 46.1 & 87.5 & 91.7 & 79.2 & - \\
& & 7 & & & & & \\
PPV (\%) & 70.2 & 68. & 68.9 & 75 & 92 & 82.8 & - \\
& & 9 & & & & & \\
OR (n) & 7.9 & 4.4 & 8.9 & 2.3 & 19.5 & 7.6 & - \\
Prevalence (\%) & 60 & 60 & 56.7 & 60 & 60 & 60 & - \\
All & & & & & & & \\
Sensitivity (\%) & 69.4 & 79 & 79.9 & 37.1 & 77.4 & 44.4 & 65.8 \\
Specificity (\%) & 71.6 & 54 & 62.9 & 81.8 & 75.7 & 82.8 & 81.7 \\
PPV (\%) & 67.2 & 59 & 72 & 62.2 & 72.7 & 74.4 & 82 \\
OR (n) & 5.7 & 4.4 & 6.7 & 2.5 & 10.7 & 3.8 & 8.6 \\
Prevalence (\%) & 45.6 & 42. & 54.4 & 45.6 & 45.6 & 45.6 & 55.8 \\
& & 9 & & & & & \\
\hline
\end{tabular}

WC: Waist circumference; TG: Triglyceride; HDL-C: high density lipoprotein-cholesterol; OR: odd ratio; PPV: Positive predictive value. All values in percentage except OR.

The substituted value $(\geq 93 \mathrm{~cm})$ is close to the International Diabetes Federation cut-off point of $94 \mathrm{~cm}$ [4]. Since WC cut-off point of $\geq 93 \mathrm{~cm}$ proved better than other cut-off points among the groups, it may be used for both male and female subjects in the study population. It has been shown that the effects of obesity may vary as a function of ethnicity, thus necessitating the development of ethnic-specific values to identify individuals at greatest risk [12]. The WC cut-off point of $\geq 93 \mathrm{~cm}$ may therefore be preferred for the diagnosis of MS in hypertensive Nigerians. This is in line with a recent joint statement issued by six organizations involved in the 
study of MS. In that report, WC was assigned no specific figure but was said to be population- and countryspecific [6]. Among the Chinese, Japanese and South Asian, ethnic-specific values for WC have been advocated $[10,11]$. The WHO and AACE did not include WC as a measure of obesity, but instead, included body mass index and or waist-hip ratio, both of which were regrettably not determined in the present study.

Similarly from table 2 , HDL-C cut-off point for the male subjects $(\leq 1.0 \mathrm{mmol} / \mathrm{l})$ gave low OR (3.3), sensitivity (30.8\%) and high specificity (88\%). This suggests that the cut-off point was too high. However, any other figures for HDL-C, such as $<1.3 \mathrm{mmol} / \mathrm{l}$ or $<0.88 \mathrm{mmol} / 1$ suggested by some groups $[3,4]$ when substituted, suffered even more serious disadvantages of poor sensitivity and absolute or near absolute specificity among the male subjects. A modification that used the same cut-off point $(\leq 1.3 \mathrm{mmol} / \mathrm{l})$ for the male as well as the female patients improved the predictive value of low HDL-C among the male subjects though it increased the prevalence to the same value as $\mathrm{WC} \geq 93 \mathrm{~cm}$ (Table 3 ). This may be accepted since there were no statistically significant differences between the mean HDL-C values of the male and female subjects in the study group. Among the female subjects, the ATP III cut-off point for HDL-C was adequate giving acceptable values for OR (7.6), sensitivity (66.7\%), specificity (79.2\%) and PPV (82.8\%) (Table 2).

The OR (2.5) and sensitivity (37.1\%) calculated for FPG in the general population were low when compared with those of other parameters (Table 2).

Table 3: Comparison of ATP III criteria with modifications in HDL-C, WC and FPG cut-off points in hypertensive Nigerians

\begin{tabular}{|c|c|c|c|c|c|}
\hline & $\begin{array}{l}\text { OR } \\
(\mathrm{n})\end{array}$ & $\begin{array}{l}\text { Sensitivity } \\
(\%)\end{array}$ & $\begin{array}{l}\text { Specificity } \\
(\%)\end{array}$ & $\begin{array}{l}\text { Prevalence } \\
(\%)\end{array}$ & $\begin{array}{l}\text { PPV } \\
(\%)\end{array}$ \\
\hline $\begin{array}{l}\text { HDL-C (Males \&Females) } \\
\text { ATP III } \\
\text { ( } \leq 1.0 \& \leq 1.3 \mathrm{mmol} / 1 \text { respectively). }\end{array}$ & 3.8 & 44.4 & 82.8 & 52.9 & 74.4 \\
\hline Modification; ( $\leq 1.3 \mathrm{mmol} / 1$ for both). & 8.6 & 65.8 & 81.7 & 55.8 & 82 \\
\hline $\begin{array}{l}\text { FPG (Males \& Females) } \\
\text { ATP III }(\geq 5.6 \mathrm{mmol} / \mathrm{l}) .\end{array}$ & 2.5 & 37.1 & 81.8 & 45.6 & 62.2 \\
\hline $\begin{array}{l}\text { WHO } \\
(5.6-6.1 \mathrm{mmol} / 1,) .\end{array}$ & 5.3 & 18.0 & 96.0 & 44.8 & 57.5 \\
\hline $\begin{array}{l}\text { AACE, } \\
(6.1-7.0 \mathrm{mmol} / 1)\end{array}$ & 2.5 & 3.2 & 100 & 45.5 & 100 \\
\hline $\begin{array}{l}\text { WC (Males\& Females) } \\
\text { ATP III } \\
\text { (>102 \& >88cm respectively). }\end{array}$ & 5.7 & 69.4 & 71.6 & 45.6 & 67.2 \\
\hline $\begin{array}{l}\text { Modification } \\
(>93 \mathrm{~cm}) .\end{array}$ & 6.7 & 79.7 & 62.9 & 54.4 & 72 \\
\hline
\end{tabular}

ATP III: National Cholesterol Education Programme/ Adult Treatment Panel III criteria; WHO: World Health Organization criteria; AACE: American Association of clinical Endocrinologists criteria; WC: Waist circumference; WC: Waist circumference; HDL-C: high density lipoprotein-cholesterol; OR: odd ratio; PPV: Positive predictive value. FPG: Fasting plasma glucose. All values in percentage except OR

The figures for FPG suggested by WHO $(5.6-6.9 \mathrm{mmol} / \mathrm{l})$ and AACE $(6.1-7.0 \mathrm{mmol} / \mathrm{l})$ gave very poor sensitivity $(<20 \%)$ and absolute specificity, (100\%) (Table 3). The utility of fasting hyperglycaemia as a predictor of MS improved with the male patients and worsened with the female patients. The prevalence of hyperglycaemia among the subjects was low and when considered with its low sensitivity and the fact that sexspecific values have not been defined for plasma glucose the only inference may be that fasting hyperglycaemia may not be good predictors of MS in the study population, especially among the female subjects.

The ATP III cut-off point for fasting hypertriglyceridaemia seemed adequate for all the groups with high predictive potentials. 


\section{Conclusion}

The ATP III criteria were not wholly suitable for the diagnosis of MS in the hypertensive Nigerians. The criteria when suitable for one group may not be so for another, necessitating some modifications in the cutoff points and even in the choice of factors. The utility of the factors as predictors of the syndrome varied with sex. Since sex-specific values have not been defined for some of the factors such as FPG the only conclusion may be that such factors may not be good predictors of MS in the population studied. There may be the need to prescribe different cut-off points or even factors for the diagnosis of the MS in the male and female hypertensives. The result of this study suggested the following modifications in the ATP III criteria for the diagnosis of the MS in hypertensive Nigerians: WC; men and women $(\geq 93 \mathrm{~cm})$, fasting TG $(\geq 1.70 \mathrm{mmol} / 1)$, BP $(\geq 130 / 85 \mathrm{mmHg})$ or antihypertensive therapy, HDL-C; men and women $(\leq 1.3 \mathrm{mmol} / \mathrm{l})$ and FPG $(5.6 \mathrm{mmol} / \mathrm{l})$.

\section{References}

[1] Barclay, L. New definition of the metabolic syndrome. A newsmaker Interview with Sir George Alberti. Available at:

[2] http://www.mediscape.com/viewarticle/504382?scr=hp22lead (Accessed 05/12/09).

[3] World Health Organization. Definition, Diagnosis and Classification of Diabetes Mellitus and Its Complications. Report of W.H.O. Consultation. Part 1. Diagnosis and Classification of Diabetes Mellitus 1999. World Health Organization Department of Noncommunicable Disease Surveillance, Geneva. Available at: http://whqlibdoc.who.int/hqr/1999/who_ncd_ncs_99.2.pdf. (Accessed on 12/8/2011).

[4] National Cholesterol Education Programme. $3^{\text {rd }}$ Report of the NCEP on Detection and Treatment of high Blood Cholesterol in (Adults, Adult Treatment Panel III); final report. Circulation 2002; 106: 3143 - 3421.

[5] Alberti, K.G.M, Zimmet, P., Shaw, J. Metabolic syndrome: A new world-wide definition. A consensus statement from the International Diabetes Federation. Diabetes Med. 2006; 23: 469 - 480.

[6] Alberti, K.G.M. and Zimmet, P. and Shaw, J. International Diabetic Federation, (IDF), Epidemiology Task Force Consensus Group. The Metabolic Syndrome - a new worldwide definition. Lancet 2005; 366: 1059 - 1062.

[7] Alberti, K. G., Eckel, R. H., Grundy, S. M. et al. Harmonizing the metabolic syndrome. A joint interim statement of the International Diabetes Federation Task Force on Epidemiology and Prevention; National Heart, Blood and Lung Institute; American Heart Association; World Heart Federation International Atherosclerosis Society; and International Association for the Study of Obesity. Circulation 2009; 120: $1640-1645$.

[8] Sakkinen, P. A., Wahl, P., Cushman, M., Lewis, M. R. and Tracy, R. P. Clustering of procoagulation, inflammation and fibrinolysis variables with metabolic factor in insulin resistance syndrome. Am J Epidemiol 2001; 152: 897 - 907.

[9] Chen, W. Srinivasan, S. R. Elkasabany, A. and Berenson, G. S. Cardiovascular risk factor clustering features of in sulin resistance syndrome, (Syndrome X) in a biracial (blck-white) population of children, adolescents and young adults: The Bogahisa Heart Study. Am J Epidemiol 1999; 150: $667-674$.

[10] Gray, R. S. Fabsitz, R. R. Cowan, L. D. Lee, E. T. Howard, B. V. and Sa vage, P. J. Risk factor clustering in the insulin resistance syndrome: The Strong Heart Study. Am J Epidemiol 1998; 148: 869 - 878.

[11] World Health Organization Expert consultation. Appropriate body mass index for Asian population and its implications for policy and intervention strategies. Lancet 2004; 363: 157-163.

[12] Weiss, R., Dziura, J., Burgert, T. S., Tamborlane, M. V., Takasali, S. E., Yeckel, C.W., Allen, K., Lopes, M., Savoye, M., Morrison, J., Sherwin, R. S., Caprio, S. Obesity and the metabolic syndrome in children and adolescents. Obstet Gynecol Surv 2004; 59: $822-824$.

[13] Trinder, P. Determination of blood glucose using an oxidase-peroxidase system with a non-carcinogenic chromogen. $J$ Clin Pathol $1969 ; 22: 158-161$.

[14] Buccolo, G. and David, H. Quantitative determination of serum triglycerides by the use of enzymes. Clinical Chemistry 1973; 19: $476-482$.

[15] Allain, C. C., Poon, L. S., Richmond, W, and Fu, P. C. Enzymatic determination of total serum cholesterol. Clinical Chemistry 1974; $20: 470-475$.

[16] Bradley, V. Research resources for biomedical scientists. The Biomedical Scientist 2005; $696-700$.

[17] Kelminda, B, Leila, A. Metabolic syndrome in hypertensive subjects. Correlation between anthropometric data and laboratory findings. Diabetes Care 2007; 30: $1624-1626$.

[18] Sorkhou, E. I., Al-Qullaf, B., Al-Namash, H. A., Ben-Nakhi, A., Al-Batish, M. M. and Habiba, S. A. Prevalence of metabolic syndrome among hypertensive patients attending a primary care clinic in Kuwait. Med Princ Pract 2004; $13: 39$ - 42. 